Int. J. Electrochem. Sci., 14 (2019) 8028 - 8038

\title{
Determination of a Dimensionless Fluctuation Coefficient Using Electrochemical Impedance Spectroscopy
}

\author{
M. Saitou \\ Department of Mechanical Systems Engineering, University of the Ryukyus, 1 Senbaru, Nishihara- \\ cho, Okinawa, 903-0213, Japan \\ E-mail: saitou@tec.u-ryukyu.ac.jp
}

doi: $10.20964 / 2019.08 .52$

Received: 6 April 2019 / Accepted: 23 May 2019 / Published: 30 June 2019

Using the Randles circuit model, we determined that, for the impedance to fall on a straight line in a Cole-Cole plot, a dimensionless fluctuation coefficient that represents the quantity of the fluctuation in ion concentration near an electrode must be considered. The electrochemical impedance spectroscopy (EIS) measurement in a silver ferrocyanide-thiocyanate solution containing antimony potassium tartrate (APT) known as a leveling agent fell on a straight line in a Cole-Cole plot. The dimensionless fluctuation coefficient of silver ions, which was shown to be independent of the APT concentration, was determined to be 8.9 by comparison with calculations of the Randles model impedance. In addition, according to the derived formulae, exchange current density and equilibrium concentration of silver ions were determined.

Keywords: Dimensionless fluctuation coefficient, Cole-Cole plot, EIS, Randles circuit model, APT

\section{FULL TEXT}

(C) 2019 The Authors. Published by ESG (www.electrochemsci.org). This article is an open access article distributed under the terms and conditions of the Creative Commons Attribution license (http://creativecommons.org/licenses/by/4.0/). 